\title{
Assessing Maturity for e-Government Services
}

\author{
Egidijus Ostašius \\ Vilnius Gediminas Technical University, Department of Fundamental Sciences, Lithuania \\ Egidijus.Ostasius@vgtu. It
}

\begin{abstract}
E-service development as an integral part of e-government is growing area so the assessment of maturity of these services is becoming increasingly relevant. This paper presents more precise method for the evaluation of e-service maturity. It is based on stage model, the service division into the components - operations and the statistics of intensity of their usage in traditional and electronic space. The method is illustrated by data sample for the driver license e-service maturity evaluation. It can be applied to both the online service compared to the same at different stages of its evolution, or installed in different organizations (e.g. municipalities) or even in different countries, as well as comparing maturity among different e-services.
\end{abstract}

Keywords: e-government, public e-service, assessment, e-service maturity, benchmarking, sophistication.

\section{Introduction}

Electronic government (or e-government) has not a long history since the first official government sites appeared in the middle of 1990s delivering information and services. There exist a number of different definitions of e-government [1]. According to one of them e-government beside constituency participation, governance by transforming internal and external relationships is a continuous optimization of service delivery through technology, the Internet, and new media [2]. Electronic services (or e-services), the core parts of e-government are in continuous processes of improvement and evolutional changes in order to provide better services to their customers. That causes the need for the measure of how big these trends of changes are and what is the growth in such kind of evolution. A number of methods and models were proposed and applied (e.g., [3], [4], [5], [6]). Mostly they are based on stage models that describe and predict main aspects of e-government and supporting e-services.

Stage models are used for evaluating and benchmarking the level of maturity of the developed e-services [7], categorizing, evaluating the progress and guiding the directions for public service development, help in understanding the current e-service status [8], for directing where to go and assessing the developing process [9]. They are also used to rank the countries for e-government implementations and their trends (e.g., [7], [10], [11], [12]) although because of differences in assessment methods these surveys show some very different results [13]. Usually stage models are defined 
by various stages of e-government, which reflect the degree of technical sophistication and interaction with users [14] (e.g., (1) information necessary to start the procedure to obtain the service available on the website(s), (2) interaction: downloadable or printable form to start the procedure to obtain the service on the website(s), (3) two-way interaction: electronic forms to start the procedure to obtain the service on the website(s), (4) transaction: full electronic case handling of the procedure by the service provider, (5) proactive, automated service delivery [7]). But after the empirical investigation of real e-services there do not appear to be discernible steps or stages in e-government. Rather, after an initial e-government presence, governments adopt e-government slowly and incrementally [15] development of services is not sudden jumps, but even increase. That leads to the thoughts that there is a need for developing methods and models that describe egovernment and their e-services more accurate.

On the other hand these models just express the potency of examined cases of egovernment services but do not consider the structure of e-services and the intensity (volumes) of their usage in real world. It's often the will "If we build it, they will come!" not come true. At the end of the day, e-government is what it is, not what it was predicted to be [15]. That prompts that evaluating the e-services we should take into account not only the potential possibilities of the provided e-service that are based on the speculations of e-government models - the 'potential maturity' of eservice but also take into consideration the empirical data of the usage of the eservices.

The investigation of the problem why the e-service with high maturity level is not used in such volumes as it was expected is far beyond the scope of this paper. In this article, we ask if the e-services with the same maturity level ('potential maturity') but different intensity of their online usage should be evaluated at the same rate.

We present more accurate assessment method for e-service maturity that is based on stage models, service decomposition into the components - operations, which are related to the total intensity of their usage, as well as intensity of online service usage. In our case we decided on the stage model [7] that was approved and used for several years by collaborating Member States for the eGovernment performance benchmarking in EU though the method can be used for any other type of stage model that were listed before. The method first of all can be used for self-assessment of trends of maturity of e-services in different time periods of e-service development evolution. It could be also useful for benchmarking, comparing different e-services with each other or indicating weak aspects of the e-service and eliminating these weaknesses by appointing directions for further development. Finally, the presented method was adopted for use with the set of evaluation criteria that are based on generic e-service model [16] when assessment is carried out in accordance with the stage model definitions for each criterion.

\section{Case Study: Driver's License Service}

We'll analyze and evaluate the maturity of the driver's license (DL) service - a standard procedure to obtain a driver's license for a personal vehicle not for professional use which is one of the 'traditional benchmark' public services [7]. 
In our case DL service structure is composed of service operations (marked as 1, 2, $\ldots, 5)$ that are detailed by service cases (marked as 3 a, $3 \mathrm{~b}, \ldots, 5 \mathrm{~b}$ ). DL service operations:

1 Issue a new driver license.

2 Change/renew driver license.

3 Change of status of driver license: 3 a. activate driver license, 3 b. reports on driver license losses.

4 Obtain information on the right to drive or driver license: 4 a. obtain information on the right to drive: granted / deprived, 4 b. obtain information on driver license: produced / sent / handed, $4 \mathrm{c}$. obtain information on driver license validity, $4 \mathrm{~d}$. obtain information from driver license register, $4 \mathrm{e}$. obtain information on driver examination: statement / protocol / reference.

5 Obtain information on driver license production or expiration: 5 a. obtain information on driver license production, 5 b. obtain information on expiration of driver license.

A particular DL service may consist of one or more non contradictory operations. As the maturity level for different operations of the service may be different we'll apply the model for every separate operation individually.

Service operations number 1 and 2 may be assessed by $3^{\text {rd }}$ or $4^{\text {th }}$ stage depending on service conditions: $3^{\text {rd }}$ stage - if it is not possible to accept required data not electronically and customer must physically deliver lacking data documents to the service provider office; $4^{\text {th }}$ stage - if all required data for the service are accepted online. The service operations number 3 and 4 may be assessed by: $3^{\text {rd }}$ stage - if the request is delivered to service provider not electronically; $4^{\text {th }}$ stage - if the request is delivered online. The service operation number 5 may be assessed by $4^{\text {th }}$ or $5^{\text {th }}$ stage: $4^{\text {th }}$ stage - if the customer of the service did not provide contact data that could be used to send him information and $5^{\text {th }}$ stage - if service provider prompts the customer automatically online.

According to [7] the overall DL service maturity level would be assessed to stage 5 that correspond to the possibly highest evaluation level for this kind of service. It is because the current method is referenced to the highest evaluation of the service operation that is service operation number 5 in our case and that satisfy the model $5^{\text {th }}$ stage conditions. But such an assessment of the service for DL service does not fit for the rest operations of the service. Though the service operation number 5 would be assessed to stage level 5 is it correct to assess the whole service to $5^{\text {th }}$ stage level? It is obvious that such a method of service evaluation when the service is composed of operations with different maturity level is not precise.

\section{E-service Maturity Level Assessment Method}

E-service maturity level according to the method described in [7] is formed as follows: the maturity level evaluation $M_{n}$ for the online service $n,(n=1, \ldots, N, N-$ number of services that participate in evaluation) is calculated in percentages using 
current stage model level evaluation of the service $\mathrm{K}_{\mathrm{n}}$ and highest possible stage model level $\mathrm{H}_{\mathrm{n}}$ for the service $\mathrm{n}$ :

$$
M_{n}=K_{n}\left(100 / H_{n}\right)
$$

where $n-$ index of the service, $n=1, \ldots, N$,

$M_{n}$ - maturity evaluation level for service $n$,

$H_{n}$ - possible highest stage model level for service $n: H_{n} \in\{1,2,3,4,5\}$ (according to recommendations for DL service [7] this level is 5),

$\mathrm{K}_{\mathrm{n}}$ - stage model level evaluation defined by the experts according to the definition of the stage model levels: $K_{n} \in\{0,1,2,3,4,5\}$, when the highest evaluation level is $\mathrm{H}_{\mathrm{n}}=5$.

The overall maturity level $\mathrm{M}$ for the services that participate in assessment is:

$$
\mathrm{M}=1 / \mathrm{N} \underset{\mathrm{n}=1}{\mathrm{~N}} \mathrm{M}_{\mathrm{n}}
$$

We'll apply formula (1) for the maturity level evaluation for every separate operation $\mathrm{j}$ of service $\mathrm{n}$. In this case the maturity level evaluation $\mathrm{M}_{\mathrm{n} 1}^{\prime}$ of service $\mathrm{n}$ is calculated as follows:

$$
\mathrm{M}_{\mathrm{n} 1}^{\prime}=1 / \mathrm{P}_{\mathrm{n}} \sum_{\mathrm{j}=1}^{\mathrm{P}_{\mathrm{n}}} \underset{\mathrm{i}=1}{\mathrm{R}_{\mathrm{jn}}}\left(1 / \mathrm{R}_{\mathrm{jn}} \sum_{\mathrm{ijn}}\left(100 / \mathrm{h}_{\mathrm{jn}}\right)\right)
$$

where $i$-evaluation index for operation $j$ of service $n, i=1, \ldots, R_{j n}$,

$R_{\mathrm{jn}}-$ number of evaluations of operation $\mathrm{j}$ for service $n$,

$\mathrm{k}_{\mathrm{ijn}}$ - evaluation rate for evaluation $\mathrm{i}$ of operation $\mathrm{j}$ for service $\mathrm{n}$ : $\mathrm{k}_{\mathrm{ijn}} \in\{0,1,2,3,4,5\}$,

$h_{\mathrm{jn}}-$ possible highest evaluation rate for operation $j$ of service $n: h_{j n} \in\{1,2,3,4,5\}$, $\mathrm{k}_{\mathrm{ijn}} \leq \mathrm{h}_{\mathrm{jn}}$.

Evaluation formula (3) we'll make more accurate by introducing usage coefficients $\alpha_{j n}$ for operation $j$ of service $n$ that correspond to the intensity of the service operation usage as a part of the intensity of the usage of all service operations. In this case maturity level evaluation $\mathrm{M}_{\mathrm{n} 2}^{\prime}$ for service $\mathrm{n}$ :

$$
\mathrm{M}_{\mathrm{n} 2}^{\prime}=\underset{\mathrm{j}=1}{\sum_{\mathrm{n}} \alpha_{\mathrm{jn}}}\left(1 / \mathrm{R}_{\mathrm{jn}} \sum_{\mathrm{i} \mathrm{k}_{\mathrm{ijn}}}\left(100 / \mathrm{h}_{\mathrm{jn}}\right)\right)
$$

where

$$
\alpha_{j n}=\omega_{j n} / \sum_{j=1} \omega_{j n}
$$

$\omega_{\mathrm{jn}}-$ total intensity of usage of operation $\mathrm{j}$ for service $\mathrm{n}$ (number of operations $\mathrm{j}$ for service $\mathrm{n}$ per time period $\mathrm{T}$ ) via traditional and electronic (online) space, 


$$
\underset{j=1}{P_{n}} \alpha_{j n}=1, \text { for every } n .
$$

After collected statistics on intensity of the usage of operation $\mathrm{j}$ for e-service $n$ we can evaluate the volume $S^{\prime}{ }_{n}$ of the service which is delivered online:

$$
\mathrm{S}_{\mathrm{n}}^{\prime}=1 / \mathrm{P}_{\mathrm{n}} \sum_{\mathrm{j}=1}^{\mathrm{P}_{\mathrm{n}}} \beta_{\mathrm{jn}} 100
$$

where $\beta_{\mathrm{jn}}=\varphi_{\mathrm{jn}} / \omega_{\mathrm{jn}}$,

$\varphi_{\mathrm{jn}}$ - intensity of online operations - number of online operations $\mathrm{j}$ for service $\mathrm{n}$ per time period $\mathrm{T}$,

$$
1 / \mathrm{P}_{\mathrm{n}=1}^{\mathrm{P}_{\mathrm{n}}} \sum_{\mathrm{jn}} \leq 1 \text {, for every } \mathrm{n} .
$$

The statistics on intensity of the usage of operation $\mathrm{j}$ for e-service $\mathrm{n}$ we'll use for the service maturity evaluation $\mathrm{M}_{\mathrm{n} 3}$ :

$$
\begin{aligned}
& \begin{array}{lll}
\mathrm{P}_{\mathrm{n}} & \mathrm{R}_{\mathrm{jn}} \quad \mathrm{P}_{\mathrm{n}}
\end{array} \\
& \mathrm{M}_{\mathrm{n} 3}^{\prime}=\Sigma \Sigma\left(\varphi_{\mathrm{ijn}} / \Sigma \omega_{\mathrm{ln}}\right) \mathrm{k}_{\mathrm{ijn}}\left(100 / \mathrm{h}_{\mathrm{jn}}\right) \\
& \mathrm{j}=1 \quad \mathrm{i}=1 \quad \mathrm{l}=1
\end{aligned}
$$

where $\varphi_{\mathrm{ijn}}$ - intensity of online operations (number of online operations $\mathrm{j}$ for service $\mathrm{n}$ per time period $\mathrm{T}$ ) for evaluation $\mathrm{i}$,

$\omega_{\text {ln }}$ - total usage intensity of operation 1 for service $n$ (number of operations 1 for service $\mathrm{n}$ per time period $\mathrm{T}$ ) in traditional and electronic (online) space.

We'll use (2) formula for the total evaluation of maturity $\mathrm{M}^{\prime}$ for all e-government services:

$$
\begin{gathered}
\mathrm{M}^{\prime}=1 / \mathrm{N} \\
\sum \mathrm{n}_{\mathrm{n}=1} \sum_{\mathrm{j}=1 \mathrm{i}=1 \quad \mathrm{R}_{\mathrm{jn}}} \mathrm{P}_{\mathrm{n}} \quad \mathrm{l}=1
\end{gathered}
$$

In case, when there is a set of evaluation criteria (e.g., see [17]) that are defined by stage models, the maturity evaluation $M^{\prime}{ }_{n 4}$ of every operation $j\left(j=1, \ldots, P_{n}\right)$ for service $n(n=1, \ldots, N)$ instead of one we use several criteria $k_{n j l}^{\prime}\left(l=1, \ldots, L_{n j}\right)$ with possible highest evaluation rate $\mathrm{h}_{\text {njl }}$ and "weights" $w_{\text {njl. }}$. Here formula (6) will be as follows:

$$
\mathbf{M}_{n 4}^{\prime}=1 / \mathrm{P}_{\mathrm{n}} \mathrm{P}_{\mathrm{n}} \alpha_{\mathrm{jn}} \sum_{\mathrm{j}=1} \mathrm{~L}_{\mathrm{nj}} w_{\mathrm{njl}}\left(\mathrm{k}_{\mathrm{njl}}^{\prime}\left(100 / \mathrm{h}_{\mathrm{njl}}\right)\right)
$$

where $\quad 1-$ evaluation criteria index for operation $j$ of service $n, l=1, \ldots, L_{n j}$, $\mathrm{L}_{\mathrm{nj}}$ - number of evaluation criteria for operation $\mathrm{j}$ of service $n$, 
$\mathrm{k}_{\mathrm{njl}}^{\prime}$ - evaluation rate according to the criterion 1 of operation $\mathrm{j}$ for service $n$,

$\mathrm{h}_{\mathrm{njl}}$ - possible highest evaluation rate of criterion 1 for operation $\mathrm{j}$ of service $\mathrm{n}, \mathrm{k}^{\prime}{ }_{\mathrm{njl}} \leq \mathrm{h}^{\prime}{ }_{\mathrm{njl}}$,

$w_{\mathrm{njl}}-$ "weight" for evaluation criterion 1 of operation $\mathrm{j}$ of service $\mathrm{n}$,

$\mathrm{L}_{\mathrm{nj}}$

$\sum w_{\mathrm{njl}}=1$, for every $\mathrm{n}$ and $\mathrm{j}$.

$1=1$

\section{E-service Maturity Evaluation Sample}

For the method illustration we'll use artificial data that show service maturity evaluations in different situations of evolution of DL service development. E-service maturity evaluations are presented graphically in Fig. 1. (For more detailed data refer to Electronic Table in [18]). Different cases A, B, C, D, E and F represent DL service with different usage intensity and different maturity level for the operations of the service.

In our sample every operation $\mathrm{j}$ for service $\mathrm{n}$ (DL service) is evaluated according to 2 possible maturity levels: lower and highest possible maturity evaluation rate $\left(\mathrm{R}_{\mathrm{j} n}=2\right.$; $\mathrm{j}=1, \ldots, 5)$ :

1 Issue a new driver license;

1.1 if not all data are accepted online this operation is evaluated in level 3;

1.2 if all data are accepted online this operation is evaluated in level 4.

2 Change/renew driver license;

2.1 if not all data are accepted online this operation is evaluated in level 3;

2.2 if all data are accepted online this operation is evaluated in level 4.

3 Change of status of driver license:

3.1 if the messages about the DL status is transmitted not electronically this operation is evaluated in level 3;

3.2 if the messages about the DL status are transmitted online this operation is evaluated in level 4.

4 Obtain information on the right to drive or driver license:

4.1 if the request and data are transmitted not electronically this operation is evaluated in level 3;

4.2 if the request and data are transmitted online this operation is evaluated in level 4.

5 Obtain information on driver license production or expiration:

5.1 if responding to the request of the customer information is transmitted online this operation is evaluated in level 4;

5.2 if information is transmitted online without the request of the customer (proactively) this operation is evaluated in level 5. 


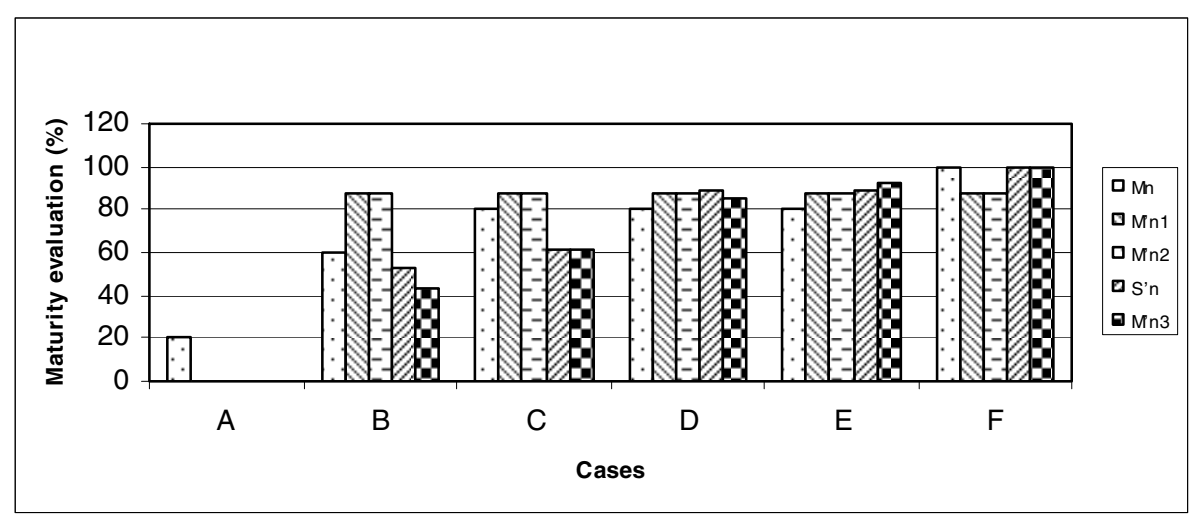

Fig. 1. E-service maturity evaluations

Case A presents situation when there is no online service operation though some general information is presented in official web site: maturity level 1. Case B presents situation when some service operations are online but evaluated at the lower rate: maturity level 3. Cases C, D and E represent intermediate situation when service operations are in two levels: maturity level 3 and 4. Case F represent situation when all service operations are evaluated in the highest rates that means the service has fully matured.

Comparing maturity evaluations (see Fig. 1) we'll notice that evaluation $\mathrm{M}_{\mathrm{n} 3}^{\prime}$ represents the maturity trend more accurately comparing it with $M_{n}, M_{n 1}^{\prime}$ and $M_{n 2}^{\prime}$ evaluations that ignore the usage intensity of online service operations in different levels of their maturity and that's these evaluations are not informative in this case. When the usage intensity of service operations is the same for different service operation evaluation (cases $\mathrm{C}, \mathrm{D}$ and $\mathrm{E}$ ) service maturity evaluation $\mathrm{M}_{\mathrm{n} 3}$ grows according to the growth of service operations: more usage intensity in higher maturity level higher maturity of the service. Evaluations $M^{\prime}{ }_{n 2}$ and $M_{n 3}^{\prime}$ for every separate operation of the service represent its own maturity.

In real situations in order to evaluate the service maturity the experts should make a decision for every separate operation of the service on the level of the maturity and they should apply presented formulas to calculate the total service maturity using the statistics of the operation usage. It may be helpful to use Electronic Table similar to presented in [18].

\section{Conclusions and Future Work}

This article proposed a more accurate method for assessing maturity of e-services. The assessment method is based on stage models, service decomposition into the components - operations. Evaluation of maturity of e-service depends on statistics such as the total intensity of the usage of every separate operation and the intensity of the usage of online service operation. The option of the e-service maturity evaluation 
is presented when there is used more than one criterion for maturity evaluation of every operation of the service. The advantage of the method was illustrated by modeling evaluation of the service with artificial data.

Still, there are several requirements that should be satisfied to be able to use the method in practice. First of all the service should be accurately decomposed into separate operations. There should be collected reliable statistical information of the usage of each operation in traditional and electronic space.

The method is focused to be used for self-assessment of maturity of e-services in their development process or for benchmarking, for comparing different e-services one with each other or for comparing the same e-services that are provided by different administrations (e.g., municipalities) or even in different countries.

For the future the presented method should be tested and validated for the maturity evaluating on real data of e-services.

\section{References}

1. Jansen, A.: Assessing E-government progress - why and what. In: Tessem, B.J., Iden og, G., Christensen, G. (eds.) NOKOBIT 2005. Department of EGovernment Studies, University of Oslo, Norway (2005), ISBN 8280330267, ISSN 15041697, http://www.uio.no/studier/emner/jus/afin/FINF4001/h05/ undervisningsmateriale/AJJ-nokobit2005.pdf

2. Gartner Group: Key issues in E-Government Strategy and Management. Research Notes, Key Issues (2000)

3. Baum, C., Maio, A.D.: Gartner's Four Phases of E-Government Model. Gartner Inc. (2000)

4. Layne, K., Lee, J.: Developing fully functional E-government: A four stage model. Government Information Quarterly 18, 122-136 (2001)

5. Ronaghan, S.A.: Benchmarking E-Government: A Global Perspective. United Nations Division for Public Economics and Public Administration and American Society for Public Administration, New York (2001)

6. Hiller, J., Belanger, F.: Privacy strategies for electronic government. PricewaterhouseCoopers (2001)

7. 9th Benchmark Measurement. Digitizing Public Services in Europe: Putting ambition into action. Prepared by Capgemini, Rand Europe, IDC, Sogeti and DTI (2010)

8. ANAO. Electronic Service Delivery, including Internet use by Commonwealth Government Agencies, Australian National Auditing Office, Canberra, Australia (1999)

9. SAFAD. The 24/7 Agency: Criteria for 24/7 Agencies in the Networked Public Administration, Statskontoret, 41, Sweden (2000)

10. United Nations. E-Government Survey 2010. Leveraging e-government at a time of financial and economic crisis, p. 95 (2010)

11. West, D.M.: Improving Technology Utilization in Electronic Government around the World, 2008. Center for Public Policy, Brown University, US (2008),

http: / / www.brookings.edu/ /media/Files/rc/reports/2008/

0817_egovernment_west/0817_egovernment_west.pdf 
12. The Economist. Intelligence Unit. Digital economy ranking 2010. Beyond e-readiness. IBM (2010),

http://graphics.eiu.com/upload/EIU_Digital_economy_rankings_ 2010_FINAL_WEB.pdf

13. Vintar, M., Nograsek, J.: How much can we trust different egovernment surveys? The case of Slovenia. Information Polity 15(3), 199-213 (2010),

http://www.fu.uni-lj.si/iiu/Clanki/

How_much_can_we_trust_different_e-government_surveys_The_

case_of_Slovenia.pdf

14. Moon, M.J.: The Evolution of E-Government among Municipalities: Rhetoric or Reality? Public Administration Review 62(4) (2002)

15. Coursey, D., Norris, D.F.: Models of E-Government: Are They Correct? An Empirical Assessment. Public Administration Review 68(3) (2008)

16. Ostasius, E., Petraviciute, Z.: Modeling e-services in public sector. INFORMACIJOS MOKSLAI 53 (2010) ISSN 1392-0561, http: / /www. leidykla.eu/en/journals/informationsciences/information-sciences-2010-vol-53/

17. Ostasius, E., Petraviciute, Z.: Applying e-Service Model in Assessment and Comparison of Services. In: Camarinha-Matos, L.M., Boucher, X., Afsarmanesh, H. (eds.) PRO-VE 2010. IFIP AICT, vol. 336, pp. 443-450. Springer, Heidelberg (2010)

18. DL Service Assessment: maturity evaluation data. Electronic Table (2011), http://e-stud.vgtu.1t/files/dest/13822/

dl_service_assessment.xls 